\title{
IMPROVING PROCESS PLANNING THROUGH SEQUENCING THE OPERATIONS
}

\author{
N. Volarevic ${ }^{1}$, P. Cosic $^{1}$ \\ ${ }^{1}$ Department of Industrial Engineering, Faculty of Mechanical Engineering and Naval Architecture, \\ University of Zagreb, Croatia
}

KEYWORDS: Process Planning, Sequencing the Operations, Applied Matrix Procedure.

\begin{abstract}
The intention of this paper is to give some methodical approach in process planning. Within this it covers the problem of defining the sequence of operations. Quality of the product, production time and production cost determine sequence of operations. The purpose is to analyse their influences and how to apply them in making decisions. Matrix of anteriorities sometimes generates multiple solutions. Understanding these influences could lead to solution of these problems.
\end{abstract}

\section{INTRODUCTION}

One of the purposes of our research is to promote such systematic thinking among students in the field of process planning. The solution has to systematize process planning making it easier to analyze machining processes needed to produce the part considering costs, time of production and functional demands. It is also a step forward to define criteria that could be integrated in intelligent process planning.

From a study on process planners, it appears that they rely on experience and intuition. As different process planners have different experience, it is no wonder that for the same part, different process planners will design different processes. The experienced process planner usually makes decisions based on comprehensive data without breaking it down to individual parameters. There is no time to analyse the problem. Understanding and a methodical thinking flow will improve the performance of the process planner. Good interpretation of the part drawing includes mainly dimensions and tolerances, geometric tolerances, surface roughness, material type, blank size, number of parts in a batch, etc. Logical approach in a process planning, as very complicated, multilevel and comprehensive approach of generating alternative process plans could be divided to:

a) selection of primary processes,

b) selection of machine tools and tools,

c) sequencing the operations according to precedence relationships.

Intention is to discuss part of process planning regarding sequencing the operations according to precedence relationships.

Process planning can be defined by a sequence of activities. Managing of a company [1] calls for many economic decisions such as the economics of manufacturing, a certain product, 
capital investment and cash flow needs, type and number of machines needed, number of employees, due date of delivery, layout etc. A decision implementation has to be based on intuition, on partially estimated data or accurate data. Process planning has to provide the background for economic evaluation. For example, when a new product is introduced in the company, the finance department wants to know its manufacturing costs. Today, two methods are used to try to overcome this dilemma and to shorten the process generation time. One is to use a computer, i.e. CAPP. Hovewer, although research and development efforts in the field of CAPP over the past two decades have resulted in numerous experimental CAPP systems, they have had no significant effect in manufacturing planning practice. Another method is to constantly improve the process planner's intuition, knowledge and expertise. [2]

\section{QUALITY, PRODUCTION TIME AND COST}

Process planning could be presented like a balance between producing a part meets functional requirements, minimal production time and minimal production cost. Relation between part manufacturing, production time and cost certainly exists but is not always very clear. All three have same inputs and in most cases they are machine type, selection of tool, how a part is fixed during process, machining parameters and few others. All this inputs affect this criterion. It was presumed that achieving a functional part should be the most important criterion. If the process is not set to be able to produce a part that meets all geometric and dimensional constrains, surface roughness, surface hardness and many other requirements then there is no sense to talk about cost and production time. Defining the sequence of operations is led primarily by this criterion, to make the process plan that is able to produce a part of required quality.

Often there is a need for additional criterion. A part feature or a number of features could be made according to different process plans. All of this process plans give a part of sufficient quality. To be able to evaluate this process plans it is necessary to take into consideration production time and production costs. In the paper mentioned principal was shown in making decisions related to sequence of operations. It was presumed that loss of time caused by machine change or tool change or fixture change affects price of part production. It also affects quality but within allowed limits.

\section{IMPORTANCE OF SEQUENCING THE OPERATIONS}

The operations defined in process planning have to be put in certain order according to precedence relationships based on technical or economical constraints. Operations sequencing depends on many influences like:
a) nature of the material,
b) general shape of the part,
c) required level of accuracy,
d) size of the raw material,
e) number of parts in the batch, 
f) possible choice of machine tools, etc.

One of the possible approaches is to classify different categories in the following way:

a) dimensional precedence - dimensions with a datum as anteriority

b) geometric precedence - geometric tolerances with data references as anteriorities,

c) datum precedence - case to the choice of a datum,

d) technological precedence - case of a technological constraint,

e) economic precedence - economic constraints that reduce production costs and wear or breakage of costly tools.

To achieve the nominated goal for definition of sequencing the operations is very complicated, multi-level, particular problem. Therefore, the expected difficulties in the process of solving this problem can be: pattern recognition, selection of datum, connection between machining surfaces and type of operations, machining tools, tools and positioning and work holding, etc. So, as the first step in process sequencing is selection of the simplified approach. It includes definition of:

a) codes for machining surfaces,

b) number of passes,

c) type of fine (F) / rough (R) machining,

d) definition the relevant anteriorities different types (dimensional, geometric, technological, economic).

As it is obviously, this approach expects the experienced process planner. One of the wellknown methods of finding the order of precedence of the operations is based on the use of a matrix.

Having defined all the anteriorities, it is now possible to find the right sequence of operations for machining. The consistency of the anteriorities depends heavily on the experience of the process planner. Solution is result of weighted category of anteriorities, minimal number of precedence operations and finishing of precedence operations. The chosen order of anteriorities implementation is result of higher priority associated to dimensional and geometrical features then economical aspects. The difficulty can come from the assessment of the anteriorities, which can result in contradictory conditions. In this case the process planners have to introduce additional criterion in order to solve this contradictions. At the same time process planer defines anteriorities needed to establish a matrix, he makes a table that contains possible machining processes, machines, fixture devices and tools for every feature. To solve contradictory situation the feature that precedes according to matrix is compared with the momentarily possible features in the matrix. "Values" in the table that belong to features are compared. The feature whose "values" from table are the most similar to "values" of preceding feature has advantage. The logic in this approach is that as much as possible number operations in a sequence should be done by same process on the same machine in the same fixture and using same tool. 


\section{MATHRIX METHOD - BOLT EXAMPLE}

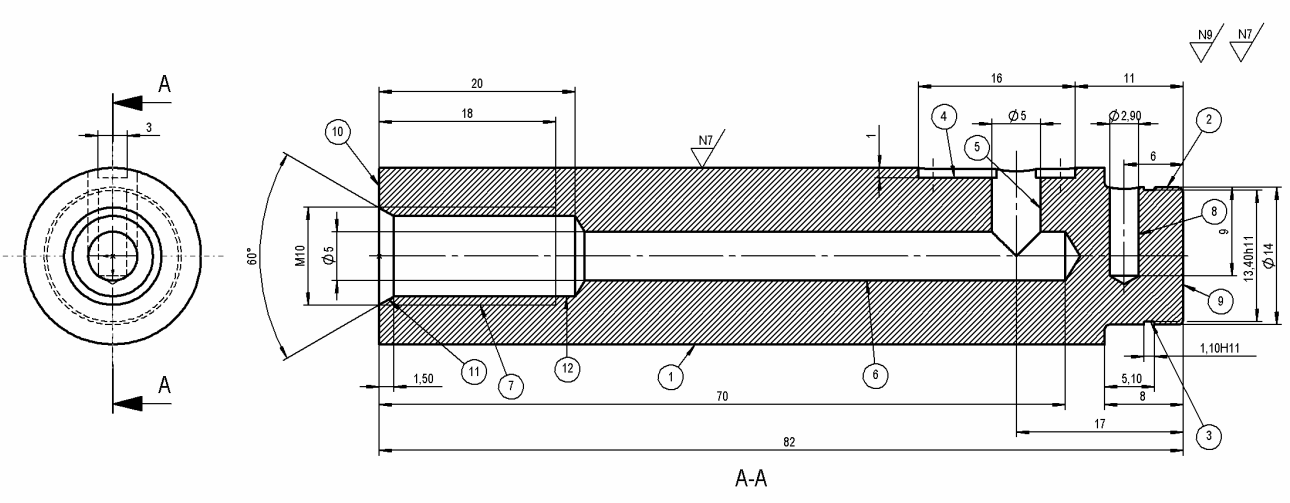

FIGURE 1. Bolt drawing

Quantity: 14000 pcs.

Material: St60-2

Taking into account geometry of the product the primary shape would be a bar $\Phi 20$.

The first step is to analyze the part drawing and "divide" the part into features. Features are made by different machining operations. According to geometric shape, tolerances, surface quality and other information a drawing contains we can select possible machines and tools by which a specific feature could be produced. For the example in Figure 1 a selection was made and is presented below in Table 1.

\begin{tabular}{|c|c|c|c|c|}
\hline $\begin{array}{l}\text { Surface }^{1} \\
\text { (Feature) }\end{array}$ & Description & Surface quality & Machine & Tool \\
\hline 1 & $\Phi 18 \mathrm{k} 6\left(\begin{array}{l}+15 \mu M \\
+2 \mu M\end{array}\right)$ & $\mathrm{Ra} 1.6 \mu \mathrm{m}$ & Lathe & \\
\hline 2 & $\Phi 14$ & $\mathrm{Ra} 6.3 \mu \mathrm{m}$ & Lathe & 7 \\
\hline 3 & $\Phi 13,40 \mathrm{~h} 11$ & $\mathrm{Ra} 6.3 \mu \mathrm{m}$ & Lathe & \\
\hline 4 & Counter bore $2 \mathrm{~mm}$ & $\mathrm{Ra} 6.3 \mu \mathrm{m}$ & Mill & (2) \\
\hline 5 & $\Phi 5$ & $\operatorname{Ra} 6.3 \mu \mathrm{m}$ & $\begin{array}{l}\text { Drilling machine } \\
\text { Mill }\end{array}$ & 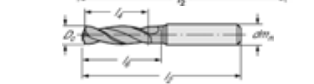 \\
\hline 6 & $\Phi 5$ dpth. 70 & $\mathrm{Ra} 6.3 \mu \mathrm{m}$ & $\begin{array}{l}\text { Drilling machine } \\
\text { Mill }\end{array}$ & ampurs \\
\hline 7 & M10 dpth.18 & $\mathrm{Ra} 6.3 \mu \mathrm{m}$ & $\begin{array}{l}\text { Drilling machine } \\
\text { Mill }\end{array}$ & 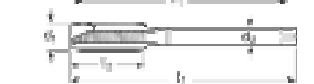 \\
\hline
\end{tabular}

${ }^{1}$ See Figure 1 


\begin{tabular}{|c|c|c|c|}
\hline$\Phi 2.90$ dpth.9 & $\mathrm{Ra} 6.3 \mu \mathrm{m}$ & $\begin{array}{l}\text { Drilling machine } \\
\text { Mill }\end{array}$ & $\frac{t}{t}+1$ \\
\hline 82 (right side) & $\mathrm{Ra} 6.3 \mu \mathrm{m}$ & Lathe & \\
\hline 82 (left side) & $\mathrm{Ra} 6.3 \mu \mathrm{m}$ & Lathe & \\
\hline $1.5 \times 60^{\circ}$ & $\mathrm{Ra} 6.3 \mu \mathrm{m}$ & $\begin{array}{c}\text { Mill } \\
\text { Drilling machine }\end{array}$ & \\
\hline Ф8.4 dpth.20 & $\mathrm{Ra} 6.3 \mu \mathrm{m}$ & $\begin{array}{c}\text { Drilling machine } \\
\text { Mill }\end{array}$ & 대를 \\
\hline
\end{tabular}

TABLE 1. Surface analysis

The problem that appears next is which feature should be machined first and more important in which order should features be done. Certainly there are restrictions regarding technology, geometric and dimensional tolerances, datum, economy (reduce production costs and wear or breakage of costly tools). Taking into account all this restrictions another table (Table 2) is made in which it is clear which features must precede before other features.

\begin{tabular}{|c|c|c|}
\hline \multicolumn{2}{|r|}{$\begin{array}{c}\text { Surface } \\
\text { (Feature) }\end{array}$} & \multirow{2}{*}{$\begin{array}{c}\text { Anteriorities } \\
10 \mathrm{R}\end{array}$} \\
\hline $1 R^{2}$ & $\Phi 18 \mathrm{k} 6\left(\begin{array}{l}+15 \mu M \\
+2 \mu M\end{array}\right)$ & \\
\hline $2 \mathrm{R}$ & $\Phi 14$ & $1 \mathrm{R}, 10 \mathrm{R}$ \\
\hline $3 \mathrm{R}$ & $\Phi 13,40 \mathrm{~h} 11$ & $2 \mathrm{R}$ \\
\hline $4 \mathrm{R}$ & Counter bore $2 \mathrm{~mm}$ & $1 \mathrm{R}, 10 \mathrm{R}$ \\
\hline $5 \mathrm{R}$ & $\Phi 5$ & $1 \mathrm{R}, 4 \mathrm{R}, 6 \mathrm{R}$ \\
\hline $6 \mathrm{R}$ & $\Phi 5$ dpth.70 & $10 \mathrm{R}, 1 \mathrm{R}, 3 \mathrm{R}, 2 \mathrm{R}$ \\
\hline $7 \mathrm{R}$ & M10 dpth.18 & $6 \mathrm{R}, 12 \mathrm{R}, 10 \mathrm{R}, 11 \mathrm{R}$ \\
\hline $8 \mathrm{R}$ & $\Phi 2.90$ dpth. 9 & $2 \mathrm{R}$ \\
\hline $9 \mathrm{R}$ & 82 (right side) & $1 \mathrm{R}, 2 \mathrm{R}, 3 \mathrm{R}$ \\
\hline $10 \mathrm{R}$ & 82 (left side) & \\
\hline $11 \mathrm{R}$ & $1.5 \times 60^{\circ}$ & $6 \mathrm{R}, 10 \mathrm{R}, 12 \mathrm{R}$ \\
\hline $12 \mathrm{R}$ & $\Phi 8.4$ dpth.20 & $6 \mathrm{R}, 10 \mathrm{R}, 1 \mathrm{R}$ \\
\hline
\end{tabular}

TABLE 2. Table of anteriorities

${ }^{2} \mathrm{R}$ - roughing 
If Table 2 is presented in matrix (Table 3), advantages from this approach are now clear. It is easy to see that the first feature to be machined is $10 \mathrm{R}$. When $10 \mathrm{R}$ is removed from table it sets free other features that were "blocked" by it. [3]

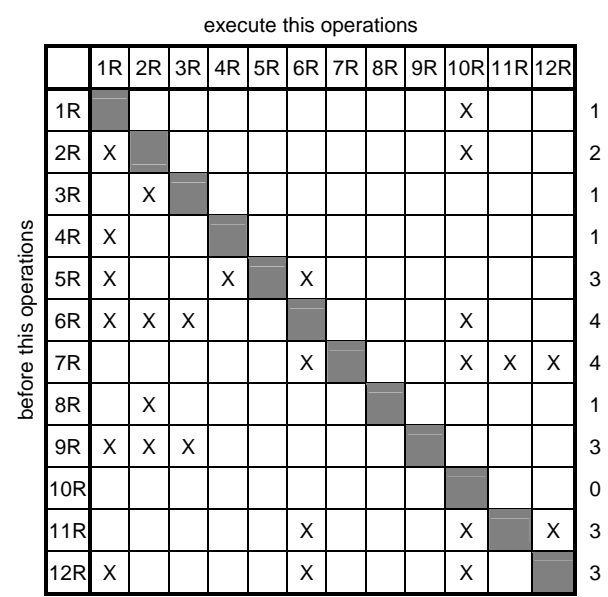

TABLE 3. Matrix of anteriorities

We are not going to analyze all the steps in the determination of operation sequence. It would be interesting to look at the situation when two or more features are not preceded by any other feature that needs to be done before. This means that all of them can be done at the same time. But this is not possible because only one feature can be machined in time. One of them must go first and then the other. In this example this situation occurs in the third step. This situation is shown in Table 4. The feature that was done before is $1 \mathrm{R}$ (Table 4a). In this step we have to decide which feature is going to be machined first $2 \mathrm{R}$ or $4 \mathrm{R}$ (Table $4 \mathrm{~b}$ ). To make this decision we need more data. Therefore another table was made, shown in Table 5.

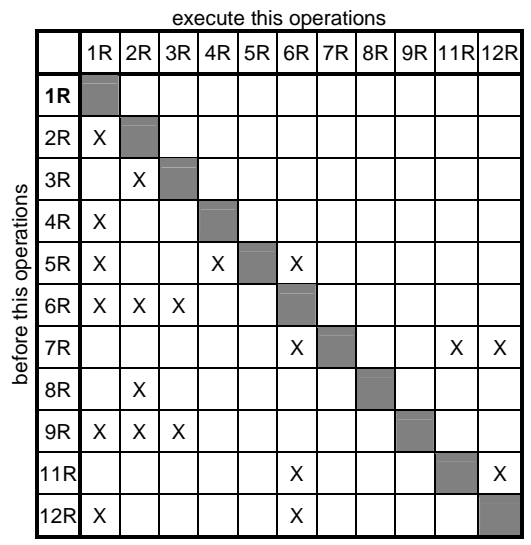

a)

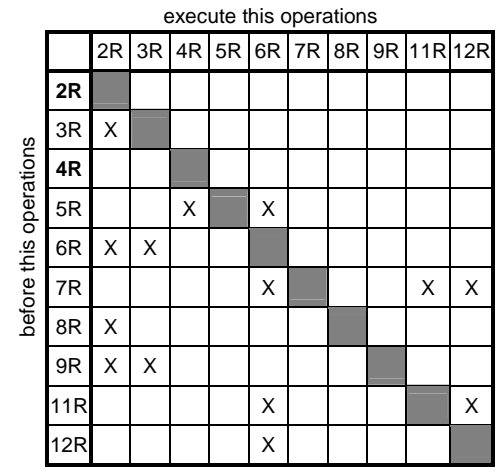

b)

TABLE 4. Matrixes of anteriorities for second step and third step 
In the Table 5. a few additional criteria were brought out. In order of significance they are:

- $\quad$ same machine (if we change the machine we change all other factors: process, fixture and tool)

- $\quad$ same process (if we change the process we change fixture type, tool and sometimes machine)

- same fixture (changing fixture needs more time than changing tool and it is recommended to do as much operations as possible in one fixture because it is more precise)

- $\quad$ same tool (the least significant factor in this list)

\begin{tabular}{|c|c|c|c|c|c|}
\hline \multicolumn{2}{|r|}{$\begin{array}{c}\text { Surface } \\
\text { (Feature) }\end{array}$} & \multirow{2}{*}{$\begin{array}{l}\text { Process } \\
\text { Turning }\end{array}$} & \multirow{2}{*}{$\begin{array}{c}\text { Machine } \\
\text { Lathe }\end{array}$} & \multirow{2}{*}{$\begin{array}{c}\text { Fixture } \\
\nabla_{10} \nabla_{9}\end{array}$} & \multirow[t]{2}{*}{ Tool } \\
\hline $1 \mathrm{R}$ & $\Phi 18 \mathrm{k} 6\left(\begin{array}{l}+15 \mu M \\
+2 \mu M\end{array}\right)$ & & & & \\
\hline $2 \mathrm{R}$ & $\Phi 14$ & Turning & Lathe & $\nabla_{10} \nabla_{9}$ & \\
\hline $3 R$ & $\Phi 13,40 \mathrm{~h} 11$ & Turning & Lathe & $\nabla_{10} \nabla_{9}$ & \\
\hline $4 \mathrm{R}$ & Counter bore $2 \mathrm{~mm}$ & Milling & Mill & $\nabla_{1}$ & (2) \\
\hline $5 \mathrm{R}$ & $\Phi 5$ & Drilling & $\begin{array}{l}\text { Drilling machine } \\
\text { Mill }\end{array}$ & $\nabla_{1}$ & +6 \\
\hline $6 \mathrm{R}$ & $\Phi 5$ dpth.70 & Drilling & $\begin{array}{l}\text { Drilling machine } \\
\text { Lathe }\end{array}$ & $\nabla_{1}$ & \\
\hline $7 \mathrm{R}$ & M10 dpth.18 & Threading & $\begin{array}{l}\text { Drilling machine } \\
\text { Mill }\end{array}$ & $\nabla_{1}$ & 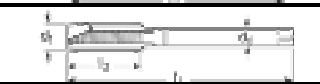 \\
\hline $8 \mathrm{R}$ & $\Phi 2.90$ dpth.9 & Drilling & $\begin{array}{l}\text { Drilling machine } \\
\text { Mill }\end{array}$ & $\nabla_{1}$ & 6 \\
\hline $9 \mathrm{R}$ & 82 (right side) & Turning & Lathe & $\nabla_{1} \nabla_{10}$ & \\
\hline $10 \mathrm{R}$ & 82 (left side) & Turning & Lathe & $\nabla_{1} \nabla 9$ & \\
\hline $11 \mathrm{R}$ & $1.5 \times 60^{\circ}$ & Countersinking & $\begin{array}{c}\text { Mill } \\
\text { Drilling machine }\end{array}$ & $\nabla_{1}$ & dis \\
\hline $12 \mathrm{R}$ & Ф8.4 dpth.20 & Drilling & $\begin{array}{l}\text { Drilling machine } \\
\text { Lathe }\end{array}$ & $\nabla_{1}$ & $x^{2}$ \\
\hline
\end{tabular}

TABLE 5. Additional criterions for solving conflict situations

If we look at the Table 5 we can see that feature $1 \mathrm{R}$ that proceeded was done by turning process on lathe. Since feature $2 \mathrm{R}$ is also done by turning on lathe which means by the same machining process as feature $1 \mathrm{R}$ it has advantage before feature $4 \mathrm{R}$. Feature $4 \mathrm{R}$ requires milling and therefore different tool and fixture. 


\section{ANALYSIS OF RESULTS}

Experience and knowledge of process planer has lot of influence on decision which features precede other features. Trying to put this in matrix of anteriority does not always give unique solution. The shape of part is usually very complex so process planer can miss or not see some relations. Knowledge and experience are limited. That is the reason why table of anteriorities is not always set up to give unique answer. This example shows logical approach that can be used to solve conflict situations in decision making regarding sequencing of operations. This approach reduces influence of intuition and gives more methodical approach suitable for intelligent process planning. [4]

\section{CONCLUSION}

One of problems process planning solves is setting up optimal sequence of operations. Sequence is set up following certain rules. Some operations have to precede other operations regarding requirements for dimensional and geometric tolerances, restrictions that come from technology, economical aspects and some other. For instance before thread cutting operation a hole should be cut and that is technology restriction. Systematizing these rules is a difficult task. The other big task is how to consider all the information we get from a technical drawing in making a process plan. This information include geometric shape, dimension and their tolerances, geometric tolerances, surface roughness, material type and its hardness, size of raw material, number of parts that need to be produced. The aim is to produce functional part at lowest price. One of the methods that can help process planers in making their decision is using a matrix of precedence. But it was shown that there are situations when matrix does not give exact answer. Two or more operations appear with the same level of precedence regarding matrix. This might be caused by process planer's lack of experience and knowledge or incomplete drawing. Anyway the matrix was not set up to give unique answer. To solve these situations other criteria was set up. It says that as much as possible number operations in a sequence should be done on the same machine by same process in the same fixture and using same tool.

\section{ACKNOWLEDGEMENTS}

This project is a part of the scientific project titled Intelligent Process Planning and Reengineering 0120-029 financed by the Ministry of Science and Technology of the Republic of Croatia. We express gratitude for the financial support for the project.

\section{REFERENCES}

1. Halevi, G., (2003), Proocess of Operation Planning, Kluwer Academic Publishers, Dordrecht.

2. Halevi, G., Weill, D., R.., (1995), Principles of Process Planning, Chapman \& Hall, London.

3. Weill, R., Spur, G., Eversheim, W., (1982), Survey of Computer-Aided Process Planning System, Analls of the CIRP Vol. 31/2/1982, pp 539-551.

4. Chang, Tien-Chien, (1990), Expert Process Planning for Manufacturing, Addison-Wesley Publishing Company, New York. 